\title{
Role of estrogens in fish immunity with special emphasis on GPER1
}

\author{
Isabel Cabas ${ }^{\mathrm{a}, *}$, Elena Chaves-Pozo ${ }^{\mathrm{b}}$, Victoriano Mulero ${ }^{\mathrm{a}}$, Alfonsa García-Ayala ${ }^{\mathrm{a}}$ \\ a Department of Cell Biology and Histology, Faculty of Biology, University of Murcia, IMIB-Arrixaca, Murcia, Spain \\ ${ }^{\mathrm{b}}$ Centro Oceanográfico de Murcia, Instituto Español de Oceanografía (IEO), Murcia, Spain
}

\section{A R T I C L E I N F O}

\section{Keywords:}

Estrogens

Estrogen receptors

GPER1

Immunity

Fish

\begin{abstract}
A B S T R A C T
It is well accepted that estrogens, the primary female sex hormones, play a key role in modulating different aspects of the immune response. Moreover, estrogens have been linked with the sexual dimorphism observed in some immune disorders, such as chronic inflammatory and autoimmune diseases. Nevertheless, their effects are often controversial and depend on several factors, such as the pool of estrogen receptors (ERs) involved in the response. Their classical mode of action is through nuclear ERs, which act as transcription factors, promoting the regulation of target genes. However, it has long been noted that some of the estrogen-mediated effects cannot be explained by these classical receptors, since they are rapid and mediated by non-genomic signaling pathways. Hence, the interest in membrane ERs, especially in G protein-coupled estrogen receptor 1 (GPER1), has grown in recent years. Although the presence of nuclear ERs, and ER signaling, in immune cells in mammals and fish has been well documented, information on membrane ERs is much scarcer. In this context, the present manuscript aims to review our knowledge concerning the effect of estrogens on fish immunity, with special emphasis on GPER1. For example, the numerous tools developed over recent years allowed us to report for the first time that the regulation of fish granulocyte functions by estrogens through GPER1 predates the split of fish and tetrapods more than 450 million years ago, pointing to the relevance of estrogens as modulators of the immune responses, and the pivotal role of GPER1 in immunity.
\end{abstract}

\section{Overview}

It is increasingly evident that estrogens are not simply reproductive hormones since they have numerous additional functions, among which their immunomodulatory role stands out. This is in part due to the presence of estrogen receptors (ERs) in immune cells, as found in both mammals and fish. Estrogens mainly exert their effects through nuclear ERs, but the identification of a membrane ER, the G protein-coupled estrogen receptor 1 (GPER1), which mediates rapid and non-genomic actions, suggests that it is worth exploring its involvement in estrogensmediated effects on immune response since the existing data are very scarce, even in mammals. The physiological and pathological effects of estrogens on the immune response, and the mechanisms involved, should be explored since that could take importance in several contexts, including estrogenic disruption, comparative immunology studies and aquaculture.

\section{Fish immune system}

Fish occupy a key phylogenetic position in the vertebrate phylogenetic tree, being the first animal group that possess an adaptive immune system. Thus, the immune system of fish is physiologically similar to that of higher vertebrates, despite certain differences, having a less complex adaptive immune system. Despite that, both innate and adaptive immune systems, and their interactions, play essential roles both in fish and mammalian immunity. Fish lack bone marrow, so, a primary organ called head kidney acts as haematopoietic organ, which also has an excretory function in its posterior portion. Moreover, they have thymus and spleen as lymphoid organs. Their innate response comprises physical barriers (epithelium and mucosa and its secretion, mucus), cellular effectors and humoral factors (Magnadottir, 2006). Thus, fish have mucosa-associated lymphoid tissue (MALT), which includes that associated with gut (GALT), skin (SALT), gill (GALT) and nasopharynx tissue (NALT) (Salinas, 2015). The innate cellular response encompasses a variety of leukocytes, including phagocytes (monocytes/macrophages and neutrophilic granulocytes) and nonspecific cytotoxic cells. Phagocytosis, the production of reactive oxygen intermediates (ROS) and nitric oxide (NO), cell degranulation, among others, are mechanisms used by innate immunity to remove pathogens. The innate immune system uses a wide spectrum of pattern recognition receptors (PRRs), such as Toll-Like Receptors (TLR), which are able to recognize pathogen-associated molecular patterns (PAMPs). Beside

\footnotetext{
* Corresponding author.

E-mail address: icabas@um.es (I. Cabas).
} 
cellular effectors, there are several humoral effectors that act in the innate defence, including bacterial growth inhibitors, viral replication inhibitors, lysozyme, lectins, natural antibodies and the complement components, among others. On the other hand, as in mammals, the fish adaptive immune response comprises a cellular and a humoral component. The cellular component can be divided into B-cells responsible for antibody production, and T-cells that mediate cell-mediated immunity. Two cell populations equivalent to mammalian B and T lymphocytes have been described in fish (Mutoloki et al., 2014). Antibodies, produced by these B lymphocytes, are key mediators in the adaptive immune response. Differently from mammals, three immunoglobulins (Ig) have been identified in teleost: IgM, the most common in serum; IgD (Edholm et al., 2011), whose relevance remains to be determined; and IgT, which seems to be specialized in mucosal immunity, and so appears to be the functional equivalent of mammalian IgA (Danilova et al., 2005; Zhang et al., 2010). Moreover, cytokines, whose expression of some of them is induced by PRR activation, are key regulators of the mammalian and fish immune response where they mediate effector phases in both innate and adaptive immunity; proinflammatory cytokines such as interleukin $1 \beta$ (IL-1 $\beta$ ) and tumoral necrosis factor $\alpha$ (TNF- $\alpha$ ) stand out in this respect.

\section{Estrogens and ERs}

Estrogens, the primary female sex hormones, are responsible for the development and regulation of the female reproductive system and secondary sex characteristics, but also have important physiological roles in males (Hess, 2003). Moreover, it is known that estrogens also have multiple non-reproductive functions. So, it is incorrect to consider estrogens simply as reproductive hormones, since that they act in a physiological manner on a broad range of non-reproductive tissues such as those of the immune, central nervous and cardiovascular systems, and have skeletal, liver, skin and kidney functions. Estrogens occur in three major natural forms: estrone $\left(E_{1}\right), 17 \beta$-estradiol $\left(E_{2}\right)$ and estriol $\left(E_{3}\right)$, the most potent and prevalent being $E_{2}$ on which this review mainly focuses. Estrogens are produced in all vertebrates, including fish, where they have an ancient evolutionary history and important endocrine functions (Eick and Thornton, 2011). They are primarily synthesized from cholesterol in gonadal tissue but also in extra-gonadal sites such as adipose tissue, skin and brain, among others (Nelson and Bulun, 2001). The synthesis and release of estrogens is regulated by the hypothalamus-pituitary-gonadal axis. The steroidogenic pathway consists of a series of steps controlled by a large number of steroidogenic enzymes, where conversion to $E_{2}$ is a key step mediated by the enzyme cytochrome P450 aromatase. Hence, the expression of this aromatase serves as an indication of estrogen production.

The physiological effects of estrogens are controlled via ERs, primarily nuclear ERs. As steroid hormones, estrogens are able to diffuse through the cell membrane and bind to and activate ERs, which belong to the nuclear receptor superfamily (Evans and Bergeron, 1988) and have a DNA binding domain and a ligand binding domain (Chawla et al., 2001; Wahli and Martinez, 1991). These ERs can shuttle between the cytoplasm and the nucleus and function as ligand-activated nuclear transcription factors that bind (directly or indirectly) to cis-acting estrogen response elements (ERE) in the promoter regions of target genes and enhancer regions (Deroo and Korach, 2006), representing the classical, nuclear or genomic actions of estrogens. In mammals, two nuclear ERs genes are encoded, ESR1 and ESR2 (ER $\alpha$ and ER $\beta$, respectively), which have a similar affinity for estrogens, although they can play distinct and non-redundant (and even opposite) roles in some context (Lewandowski et al., 2005).

Besides the genomic action of estrogens, their rapid/non-genomic/ extranuclear effects, which were identified several decades ago, could not be explained by classical ERs signaling. The forms of ERs related with these extranuclear actions exists as membrane sub-populations of nuclear ERs (Pedram et al., 2006), as isoforms of these nuclear ERs (Sun et al., 2017) or as new receptors as G protein-coupled receptors (GPCR). In this respect, various ER $\alpha$ and ER $\beta$ isoforms and splicing variants have been described (Matthews and Gustafsson, 2003). For example, ER $\alpha 36$, a new variant of ER $\alpha$, mediates estrogen-stimulated MAPK/ERK activation and is located on the plasma membrane and cytoplasm (Sun et al., 2017), while other studies indicate that this variant is predominantly localized in mitochondria of some human tissues and cells (Yan et al., 2017). So, nowadays, accumulating evidence has demonstrated that estrogens exert substantial effects on mitochondrial function (Simpkins et al., 2008).

Referring to G protein-coupled receptors (GPCR), it was not until 2005, when an orphan GPCR, GPR30, now officially designated GPER1 (Alexander et al., 2011), was identified as an estrogen-binding intracellular membrane GPCR by two independent laboratories (Revankar, 2005; Thomas et al., 2005). It was later shown that GPER1 is activated by $\mathrm{E}_{2}$ (Filardo et al., 2007; Filardo, 2002; Funakoshi et al., 2006). To date, the described mechanisms related with GPER1 activation include: rapid activation of MAPKs, ERK-1 and ERK-2 activation through the transactivation of EGFR (Filardo, 2000), PI3K signaling activation (Revankar, 2005), intracellular calcium mobilization (Revankar, 2005) and the activation of adenylate cyclase and subsequent cAMP activation (Filardo, 2002). It is known that this increase in cellular cAMP stimulates protein kinase A (PKA) signaling. One of the actions of this stimulation is that cAMP binds to the regulatory subunits of PKA, thereby promoting their dissociation from the catalytic subunits (Dermaku-Sopjani et al., 2014). The catalytic subunits released enter the nucleus by passive diffusion and phosphorylate the cAMP-responsive element (CRE)-binding protein (CREB) at Ser133. Phosphorylated CREB promotes target gene expression at promoters containing CREs (Altarejos and Montminy, 2011). Most of these mechanisms have been reviewed (Prossnitz and Barton, 2009; Prossnitz and Maggiolini, 2009; Wang et al., 2010). Moreover, the activation of GPER1 by G1, a GPER1 selective agonist (Bologa et al., 2006), does not trigger ERE-mediated activation but up-regulates the proto-oncogene CFOS by means of a non-genomic mechanism similar to $\mathrm{E}_{2}$ (Albanito et al., 2007). The use of this specific agonist together with the availability of several mouse models of GPER1 deficiency (Prossnitz and Hathaway, 2015), point to the involvement of GPER1 action in the regulation of several physiological responses and its possible relation with disease. Thus, it has been recently shown that GPER1 is involved in numerous functions of the neuroendocrine, cerebral, immune, cardiovascular, kidney and reproductive systems, as well as in endocrine regulation and metabolism. Together, these studies suggest the therapeutic potential of regulating GPER1 activity as a novel approach for the treatment of all these conditions (Prossnitz and Barton, 2011). Although few data are available, mRNA for GPER1 appears to be expressed extensively in most tissues according to several reports (Mizukami, 2010; Olde and Leeb-Lundberg, 2009).

In addition, it is important to mention that although physiological responses to estrogens are often categorized as genomic or rapid/nongenomic, much evidence exists that these artificially defined categories are connected (Ma and Pei, 2007; Moriarty et al., 2006). Moreover, nuclear and membrane ERs are considered as components of a complex mechanism in which they both cooperate pointing to the need to understand the complex mechanism involved in estrogens-mediated effects not only in reproductive tissues but in other key contexts where estrogens are involved.

Although outside the aim of this review, mention should be made of compounds able to induce estrogenic activity by mimicking or antagonizing natural estrogens, whose presence in the environment and interest in them have grown significantly in recent years. These compounds are considered endocrine disruptor chemicals (EDCs) since they can interfere with hormonally-controlled processes of humans and wildlife, resulting in adverse effects on health, growth, development and reproduction of individuals, their progeny or populations. Some of these compounds, called xenoestrogens, are natural estrogens $\left(E_{2}\right.$, 
phytoestrogens, etc.) or synthetic substances with estrogenic effects, considered as environmental contaminants and commonly found in detergents, surfactants, plastics, pesticides and industrial chemicals, including pharmaceutical estrogens (such as one of the components of contraceptive pills, $17 \alpha$-ethinylestradiol, $\mathrm{EE}_{2}$ ) and others considered as selective estrogen receptor modulators (SERM) and used at clinical level. It is known that ERs isoforms respond differently to non-steroidal estrogenic EDCs (Tohyama et al., 2016), but have similar responses to endogenous and synthetic steroidal estrogens, pointing to the different roles of ERs in responses to EDCs. Moreover, some environmental estrogens and SERMs such as tamoxifen (a known antagonist of ERs) are able to bind to GPER1 (Pang et al., 2008; Watson et al., 2011). This latter fact can be associated with the increase in the risk of endometrial carcinoma observed when tamoxifen is used in breast cancer treatment (Goldstein, 2001). Thus, the importance of estrogenic endocrine disruption by these environmental estrogens, which could affect reproductive capacity and other functions regulated by estrogens, should not be underestimated, and explains why such disruption has been extensively studied in recent years.

\subsection{ERs in fish}

Regarding nuclear ERs, most vertebrate species from the teleost lineage possess at least three ERs, a single ER $\alpha$ gene (esr1) and two ER $\beta$ genes, ER $\beta 1$ (esr2b) and ER $\beta 2$ (esr2a), due to the whole genome duplication events that occurred during ancient teleost evolution. Such is the case with gilthead seabream (Sparus aurata L.) (Pinto et al., 2006), Atlantic croaker (Micropogonias undulatus) (Hawkins et al., 2000), zebrafish (Danio rerio) (Menuet et al., 2002), goldfish (Carassius auratus) (Ma et al., 2000), European sea bass (Dicentrarchus labrax) (Halm et al., 2004), common carp (Cyprinus carpio) (Katsu et al., 2013), medaka (Oryzias latipes) (Chakraborty et al., 2011), and European eel (Anguilla anguilla) (Lafont et al., 2016). Moreover, a second form of esr1 (ERa2) has been described in rainbow trout (Oncorhynchus mykiss) (Nagler et al., 2007), Atlantic salmon (Salmon salar) (Nikoleris and Hansson, 2015) and in some cyprinid species such as Spinibarbus denticulatus (Zhu et al., 2008) and Pengze crucian carp (Carassius auratus var. pengze, Pcc) (Zheng et al., 2013); so that these species have four different ERs isotypes, two ER $\alpha$ and two ER $\beta$. In the gilthead seabream, an important Mediterranean aquaculture species in which our group has carried out numerous studies, ER $\alpha, E R \beta 1$ and ER $\beta 2$ have been identified and seen to be expressed in both reproductive and non-reproductive organs such as liver, brain, heart, kidney, intestine, gills, muscle and skin (Pinto et al., 2005).

As in mammals, the expression of GPER1 has been observed in fish, and both estrogen affinity (evaluated by using $E_{2}$ ) and signaling functions of GPER1 are well conserved between theses distantly related vertebrate groups (Thomas et al., 2010). In fish, GPER1 has been described in Atlantic croaker (Pang et al., 2008), zebrafish (Liu et al., 2009), goldfish (Mangiamele et al., 2017), gilthead seabream (Cabas et al., 2013), common carp (Majumder et al., 2015), and orange-spotted grouper (Epinephelus coioides) (Nagarajan et al., 2011). Interestingly, two GPER genes, gpera and gperb, have recently been identified in the: (i) reproductive tissues of European eel, where they have a different tissue distribution and regulation in response to experimentally-induced maturation in both sexes (Morini et al., 2017), and (ii) European sea bass, where gpera expression is mainly restricted to brain and pituitary in both sexes while gperb has a widespread tissue distribution, with higher expression levels in gill, kidney and head kidney (Pinto et al., 2017). Despite the presence of GPER1 in fish, to date, this receptor has mainly been linked with oocyte maturation (Pang et al., 2008; Pang and Thomas, 2009), brain development (Shi et al., 2013) and embryonic heart rate (Romano et al., 2017).

\subsection{Immune cells express ERs}

The presence of nuclear ERs in mammalian immune cells has been widely described, and the preponderance of esr1 gene over the esr2 gene has been described in different mammalian models, being one of the mechanism that control the effects of $E_{2}$ on the immune system (Straub, 2007). Moreover, it has been observed that the expression of these receptors in leukocytes is dependent on the leukocyte lineage, stage of development, functional phenotype and tissue microenvironment.

However, the expression of ERs in fish immune tissues and specific sub-populations of leukocytes is limited, in part due to the limited number of cell markers and cell lines available. Nonetheless, the expression of nuclear ERs in lymphoid organs and leukocytes has been described in several fish species (for references see below in this section). In some cases, this expression is constitutive but in others it is inducible or regulated by estrogen levels or by immune stimulus (for references see below in this section). Moreover, the nuclear ERs expression pattern is not identical in all the species that have been studied and, as in mammals, the expression has been detected to differ depending on cell lineage and maturation stage (for references see below in this section). With respect to GPER1, and even though it has received a growing attention since its identification, the data regarding its expression in immune cells are scarce, even in mammals. Thus, the expression of GPER1 has been described in macrophages and lymphocytes, among other mammalian immune cells (Blasko et al., 2009; Brunsing and Prossnitz, 2011; Rettew et al., 2010; Schneider et al., 2014). Moreover, in human, it has been described that GPER1 is expressed in haematopoietic stem cells but not in mature megakaryocytes (Di Vito et al., 2010), in eosinophils (Tamaki et al., 2014) and neutrophils (Rodenas et al., 2017a). However, there are only two studies that have shown the presence of GPER1 in fish immune cells (Cabas et al., 2013; Szwejser et al., 2017a).

In channel catfish (Ictalurus punctatus), $\mathrm{ER} \alpha$ is expressed in spleen, blood and head-kidney, while ER $\beta$ is only expressed in spleen (Xia et al., 2000). However, ER $\beta$ is expressed both in the spleen and in the head kidney of common sole (Caviola et al., 2007). Moreover, in channel catfish, a leukocyte lineage expression analysis showed that nuclear ER $\alpha$ and ER $\beta 2$ are differentially expressed depending on leukocyte lineage and phenotype. In addition, this same study showed that $E_{2}$ modulates the expression and functionality of the ER $\alpha$ subtypes present in all leukocytes, participating in the regulation of the immune response, and ER $\alpha$ expression is downregulated by immune stimuli such as concanavalin A (ConA) and lipopolysaccharide (LPS) (Iwanowicz et al., 2014).

A recent study carried out in carp demonstrated the expression of nuclear ER $\alpha$ and ER $\beta$, and also that of GPER1, in lymphoid tissues and head kidney monocytes/macrophages, neutrophils and lymphocytes, although ER $\beta$ was hardly detectable in peripheral blood leukocytes (Szwejser et al., 2017a). Interestingly, short-term stimulation of both monocytes/macrophages and granulocytes, with phorbol 12-myristate 13-acetate (PMA), upregulated the GPER1 expression but not that of nuclear ERs, while long-term exposure with ConA or LPS upregulated ERs expression, both nuclear and GPER1, in head kidney lymphocytes (Szwejser et al., 2017a). In juvenile rainbow trout, the four nuclear ERs transcripts described were identified in head kidney and peripheral blood leukocytes (Shelley et al., 2013). Moreover, $E_{2}$ exposure altered their expression, demonstrating that physiologically relevant concentrations of $E_{2}$ can modulate several immune functions in salmonids, although these altered levels returned to normal following the recovery period (Shelley et al., 2013). All nuclear ER forms have been identified in thymocytes and mast cells of European sea bass (Paiola et al., 2017). Moreover, viral infection up-regulated the expression of the three nuclear receptor isotypes in head kidney of zebrafish, where no modulation in gper1 expression levels was described (Lopez-Munoz et al., 2015). 
In gilthead seabream, the three nuclear ERs, ER $\alpha, E R \beta 1$ and ER $\beta 2$ (Pinto et al., 2006), are differently expressed in head kidney cell populations (Liarte et al., 2011b). Thus, macrophages and lymphocytes constitutively express only the ER $\alpha$ gene, although the macrophage stimulation with bacterial DNA drastically up-regulated the expression of ER $\alpha, E R \beta 1$ and ER $\beta 2$ genes, suggesting that the immune system increases its sensitivity to $E_{2}$ during development of the immune response (Liarte et al., 2011b). Interestingly, a species-specific cell type called acidophilic granulocyte and functionally equivalent to mammalian neutrophils (Sepulcre et al., 2002) does not express any of the three nuclear ERs (Liarte et al., 2011b). Nevertheless, a study focused on this key immune cell type showed that these cells are the head kidney leukocytes with the highest expression of GPER1, although it is also expressed in other immune tissues such as spleen (Cabas et al., 2013). In addition, gilthead seabream peritoneal leukocytes express ER $\alpha$ and GPER1, which could induced by the dietary intake of the xenoestrogen $\mathrm{EE}_{2}$ (Gomez Gonzalez et al., 2017). Moreover, both $\mathrm{EE}_{2}$ exposure and an immunization program by hemocyanin modulated head kidney ER $\alpha$ expression (Cabas et al., 2012), while in vivo G1 exposure did not modulate the protein levels of GPER1 in head kidney leukocytes (Cabas et al., 2013).

On the other hand, the presence of these receptors in immune organs during the early stages of development may indicate that steroid hormones are also involved in the maturation of the fish immune system. In addition to the presence of ERs, the constitutive expression of genes coding for steroidogenic enzymes has also been described in fish leukocytes, which suggests that the local production of estrogens also has an immunoregulatory function (Szwejser et al., 2017b).

In mammals, very data have shown that some cytokines such as IL1 $\beta$ can markedly modulate $\mathrm{E}_{2}$ levels by regulating key enzymes in the estrogens production or degradation pathway (Nakamura et al., 2003). Nevertheless, despite the few data mentioned above about the modulation of ERs by some immune stimuli such as LPS, bacterial DNA or immunization in fish immune cells, as far we know, there are no data about modulation of ERs expression and functions by cytokines.

\section{Estrogens modulate immune response}

The immunomodulatory role of estrogens is based on the presence of ERs in immune cells, which enable estrogens to act directly. As mentioned above, estrogens act on multiple non-reproductive systems, including the immune system. So, in mammals, estrogens have a key immunomodulatory role, regulating different aspects of the immune response (Straub, 2007), including haematopoiesis, differentiation, lymphocyte activation, cell polarization and cytokine production. So, estrogens have been linked with the sexual dimorphism observed in some immune disorders, such as chronic inflammatory and autoimmune diseases (Gilliver, 2010; González et al., 2010; Khan and Ansar Ahmed, 2015). Nevertheless, the estrogens-mediated effects on the immune response have also been described as complex and controversial, and they can vary with factors such as target cells type and their activation stage, physiological condition of the organism, estrogen concentration or the pool of ERs involved, among others (Straub, 2007). Due to the complexity of the immunoregulatory actions of estrogens, it is generally described that low levels of $E_{2}$ will stimulate the immune response, while high $\mathrm{E}_{2}$ levels appear to be immunosuppressive (Straub, 2007). Therefore, it is of huge interest to know the physiological and pathological effects and mechanisms of estrogens in the immune system.

\subsection{Immunomodulatory role of estrogens in fish immunity}

As shall be described below, there is evidence that supports the idea that estrogens also modulate fish immune response, although the information is more limited compared to that available for mammals. Moreover, accumulating data suggests that estrogenic EDCs may exert adverse effects on aquatic organisms by modulating immune competence. For this reason, fish have even been proposed as sentinel organisms to detect estrogenic contamination and the modulation of their immune response acting as marker of such estrogenic disruption (Casanova-Nakayama et al., 2011). In a recent study, it was demonstrated that estrogens are able to modulate miRNAs, leading to modulation of their immune functioning, and opening the possibility of new functional genome research on the teleost immune system and of identifying novel molecule biomarkers for estrogenic pollution (BurgosAceves et al., 2016, 2018). The study of estrogen-mediated effects and its mechanisms on fish immunity has implications for different contexts, such as: comparative immunology, evolutionary studies, endocrine disruption (suggesting environmental actions), aquaculture activity (anticipating and taking action), biomedicine (suggesting therapeutic targets in immune disorders where estrogens are involved), among others.

So, it is clear that a potent immune-endocrine interaction exists, which, in fish, it has an additional anatomical platform since the head kidney fulfils immune and endocrine functions. Nevertheless, as occurs in mammals, the existing data in fish are sometimes controversial and, in most cases, the mechanism that underlies these effects is poorly understood or has been little studied, perhaps because the tools available are limited. Moreover, the observed effects of estrogens on the fish immune response are in many cases species-specific and, as in mammals, depend on the concentration used and/or the time of exposure. In addition, in most studies on fish, information on whether $E_{2}$ concentrations used are physiological or not (according to the speciesspecific etrogen levels), is absent.

So, estrogens are able to modulate fish innate immunity, affecting a wide range of immune parameters or activities ranging from respiratory burst (reactive oxygen species, ROS, and NO production), lysozyme activity, phagocytosis, bactericidal activity to the complement (for references see below in this section). Moreover, they can affect aspects of fish adaptive immunity such as lymphocyte proliferation and activity, immunoglobulin levels and the development and maturation of lymphoid and myeloid cells (for references see below in this section). As evidence of this immunomodulatory role of estrogens in fish, seasondependent changes in the immune status have been seen to correlate with changes in the levels of the circulating sex hormones in numerous species (Szwejser et al., 2017c).

\subsubsection{Effects on fish innate immune response}

As regards to the influence of $\mathrm{E}_{2}$ on ROS production, a key innate immune response, the data published indicate that $E_{2}$ exposure has different effects. A stimulatory effect has been described: (i) in carp leukocytes with a short period of $\mathrm{E}_{2}$-incubation (Szwejser et al., 2017a), (ii) in channel catfish adherent kidney leukocytes at lower doses of $E_{2}$ (Iwanowicz et al., 2014) and (iii) in blood leukocytes of Japanese sea bass (Thilagam et al., 2009). A suppressive effect has been observed following: (i) intraperitoneal injection of $E_{2}$ in carp macrophages (Watanuki et al., 2002) and (ii) by in vitro long term $\mathrm{E}_{2}$ treatment in gilthead seabream head kidney leukocytes (Liarte et al., 2011b) and granulocytes (Chaves-Pozo et al., 2003). A non-modulating effect has been observed with: (i) short term treatment of $E_{2}$ in gilthead seabream head kidney leukocytes (Liarte et al., 2011b), (ii) $\mathrm{E}_{2}$ treatment in carp head kidney macrophages (Yamaguchi et al., 2001) and (iii) by in vivo $\mathrm{E}_{2}$ exposure in rainbow trout head kidney leukocytes (Shelley et al., 2013).

With respect to the phagocytic activity, a consistent inhibitory effect has been described in: (i) carp head kidney macrophages after $E_{2}$ exposure in vitro (Yamaguchi et al., 2001) and intraperitoneal injections (Watanuki et al., 2002); (ii) tilapia leukocytes with high doses of $E_{2}$ (Oreochromis niloticus $x$ O. aureus) (Law et al., 2001); (iii) sea bass head kidney leukocyte after a chronic exposure to $\mathrm{E}_{2}$ (Seemann et al., 2016); (iv) goldfish kidney macrophages (Wang and Belosevic, 1994); and (v) gilthead seabream head kidney leukocytes after short term treatments 
with high concentrations of $\mathrm{E}_{2}$ (Liarte et al., 2011b). Nevertheless, in some cases a non-modulating effect has been observed, for example after in vivo $\mathrm{E}_{2}$ exposure in rainbow trout head kidney leukocytes (Shelley et al., 2013).

A dual effect, depending on concentration, has been observed in the bactericidal activity of $\mathrm{E}_{2}$-treated channel catfish adherent kidney leukocytes, where low physiological concentrations significantly enhanced this activity, while pharmacological concentrations significantly decreased it (Iwanowicz et al., 2014).

In gilthead seabream, the complement activity is also modulated by estrogens. Accordingly, $\mathrm{E}_{2}$ enhanced complement activity after a short time of incubation period, although it decreased later (Cuesta et al., 2007). Moreover, the complement gene expression pattern was modulated by in vivo administration of $\mathrm{E}_{2}$ after bacterial infection in rainbow trout (Wenger et al., 2011).

The quintessential effect of estrogens in immunity is modulation of cytokine production which they achieve by regulating the key nuclear transcription factor NF-kB (Ghisletti et al., 2005). Accordingly, numerous authors have shown that $\mathrm{E}_{2}$ exposure affects the cytokine expression profile: (i) in sea bass, $E_{2}$ modulates the fine control of the cytokine network, including IL1 $\beta$ and TNF $\alpha$, tending to down-regulate the expression levels (Seemann et al., 2013); (ii) strongly suppresses TNF $\alpha$ expression in rainbow trout head kidney (Wenger et al., 2014); (iii) orchestrates profound alterations in the expression profile of gilthead seabream head kidney macrophages, especially those from immune-related processes and pathways (Liarte et al., 2011a); and (iv) produces a significant inhibition of the IL-1 $\beta$ accumulation resulting from several immune stimuli in gilthead seabream head kidney granulocytes (Chaves-Pozo et al., 2003). The effects of estrogens on cytokines production will have implications on innate and adaptive immune response since these cytokines are key modulators of both responses.

\subsubsection{Effects on fish adaptive immune response}

As it mentioned above, adaptive immunity is also a target for estrogenic effects. Thus, $\mathrm{E}_{2}$ exposure is able to modulate IgM levels. For example, it can promote a decrease in the plasma IgM levels in infected gilthead seabream (Cuesta et al., 2007) or in the plasma and mucosal IgM levels in rainbow trout, in which it correlates with a reduction in the number of IgM producing cells (Hou et al., 1999). Conversely, in Japanese sea bass, sublethal $\mathrm{E}_{2}$ exposure promotes a significant increase of immunoglobulin levels (Thilagam et al., 2009), while no modulation by $E_{2}$ was observed in IgM secretion from carp leukocytes (Saha et al., 2004). On the other hand, $E_{2}$ exposure leads to the involution of the thymus and significantly modifies T-cell development (Seemann et al., 2015). Thus, in nile tilapia, $E_{2}$ regulated the expression of Foxp3, a crucial transcription factor for the development and function of regulatory $\mathrm{T}$ cells, in the intestine and kidney but not in the spleen (Wei et al., 2013). In addition, it has been described that the proliferative capacity of immune cells is negatively impaired by $E_{2}$ exposure. So, in channel catfish, pre-treatment with $\mathrm{E}_{2}$ prior to mitogen stimulation led to a significant decrease in mitogen-induced proliferation of peripheral blood leukocytes (Iwanowicz et al., 2014), reduced the ability of goldfish lymphocytes to proliferate (Wang and Belosevic, 1994) and suppressed the leukocyte proliferation rate in rainbow trout, although the effect varied with exposure time (Shelley et al., 2013).

Reflecting these alterations in immune parameters, in many cases an altered susceptibility to pathogen has been observed, as in rainbow trout infected with Yersinia ruckeri (Wenger et al., 2011) or in goldfish infected by trypanosomes (Wang and Belosevic, 1994), where the $\mathrm{E}_{2^{-}}$ treated fish had lower survival rates compared to control ones. Moreover, an increased susceptibility to viral infection was observed in adult wild type zebrafish exposed to $\mathrm{E}_{2}$ and in ESR2b mutant adults (LopezMunoz et al., 2015), while no differences were observed upon bacterial infection. Finally, it has been suggested that estrogen exposure could alter the capacity of fish to respond to infection during ontogeny since this kind of exposure may promotes long-lasting effects on the humoral adaptive immune response in gilthead seabream (Rodenas et al., 2015).

\section{Relevance of GPER1 in immunity}

The specific mechanisms through which the described estrogenseffects are mediated are sometimes not well understood. In some cases, the use of specific nuclear ERs antagonist and their capacity to, partially or completely, reverse these effects, allowed the signaling pathway involved to be suggested. Nevertheless, whether GPER1 signaling is involved in all these estrogen-mediated effects is still unclear and has little been studied, even in mammals.

So far, in mammals, it has been described that GPER1 is involved in estrogen-induced thymic atrophy (Wang et al., 2008) and the impaired production of T cells in the thymus (Isensee et al., 2009). Moreover, in the context of autoimmune diseases, GPER1 knockout mice showed impaired estrogen-mediated protection (Wang et al., 2009), whereas its activation had a beneficial role in multiple sclerosis (Blasko et al., 2009). In addition, GPER1 activation promotes a suppressive phenotype in CD4 regulatory $\mathrm{T}$ cells (Brunsing et al., 2013), induces IL-10 in Th17 effector populations (Brunsing and Prossnitz, 2011), and decreases the expression of TLR4 in murine macrophages, limiting the sensitivity of these cells to LPS (Rettew et al., 2010). Finally, it has been described that GPER1 is able to regulates the life span and activation towards a pro-inflammatory phenotype of human neutrophils through several signaling pathways (Rodenas et al., 2017a) and this novel receptor has recently been associated with inflammatory diseases such as irritable bowel syndrome (Jacenik et al., 2017).

In some studies, the use of G15, an antagonist of GPER1 (Dennis et al., 2009), has also allowed to confirm that these effects are mediated via GPER1. So, for example, it was observed that G15 antagonized the immunomodulatory effects of G1 in treated macrophages, confirming that GPER1 mediates immunomodulation and neuroprotection in a mouse model of Parkinson's disease (Cote et al., 2015). Nevertheless, a new GPER1 antagonist, G36, has been identified in order to enhance the antagonist selectivity (Dennis et al., 2011).

In fish, the few existing data have also shown that GPER1 is involved in some immune processes; furthermore, some of these results are shown for the first time in vertebrates. So, it has been described that GPER1 signaling is involved in the $\mathrm{E}_{2}$-induced increase of ROS production in carp macrophages (Szwejser et al., 2017a). Moreover, it has been demonstrated that GPER1 activation regulates the functions and gene expression pattern of gilthead seabream acidophilic granulocytes, cells equivalent to mammalian neutrophils, inducing an anti-inflammatory phenotype through a GPER/cAMP/PKA/CREB signaling pathway (Cabas et al., 2013). Finally and for the first time in vertebrates, it has recently been shown that GPER1 activation induced the production of polyreactive natural antibodies (Rodenas et al., 2017b). All together, these data have shown mainly an immunosuppressive role for GPER1.

The knowledge that fish granulocyte functions are regulated by estrogens through GPER1 indicates that it is an evolutionary conserved trait and it predates the split of fish and tetrapods more than 450 million years ago. Nevertheless, the recent data regarding to GPER1 activation in bony fish granulocytes $v s$. human neutrophils have shown to be opposite in some aspect, at least in these key cells, promoting an anti- or pro-inflammatory phenotype, respectively. Therefore, while GPER1 activation by G1 induces expression of anti-inflammatory genes such as il10 or ptgs 2 and hardly modulates ROS production in bony fish granulocytes, GPER1 activation promotes the induction of pro-inflammatory genes such as $I L 1 B$ and CXCL8 and induces ROS production levels in human neutrophils (Fig. 1). Nevertheless, here it should be mentioned that GPER1 activation in carp macrophages increase ROS production (Szwejser et al., 2017a). Therefore, the species-specific effects probably depend on the time of treatment, the cell source, the cell type as well as the status of activation (Szwejser et al., 2017a). Moreover, it should be taken into account that the G1 concentration 


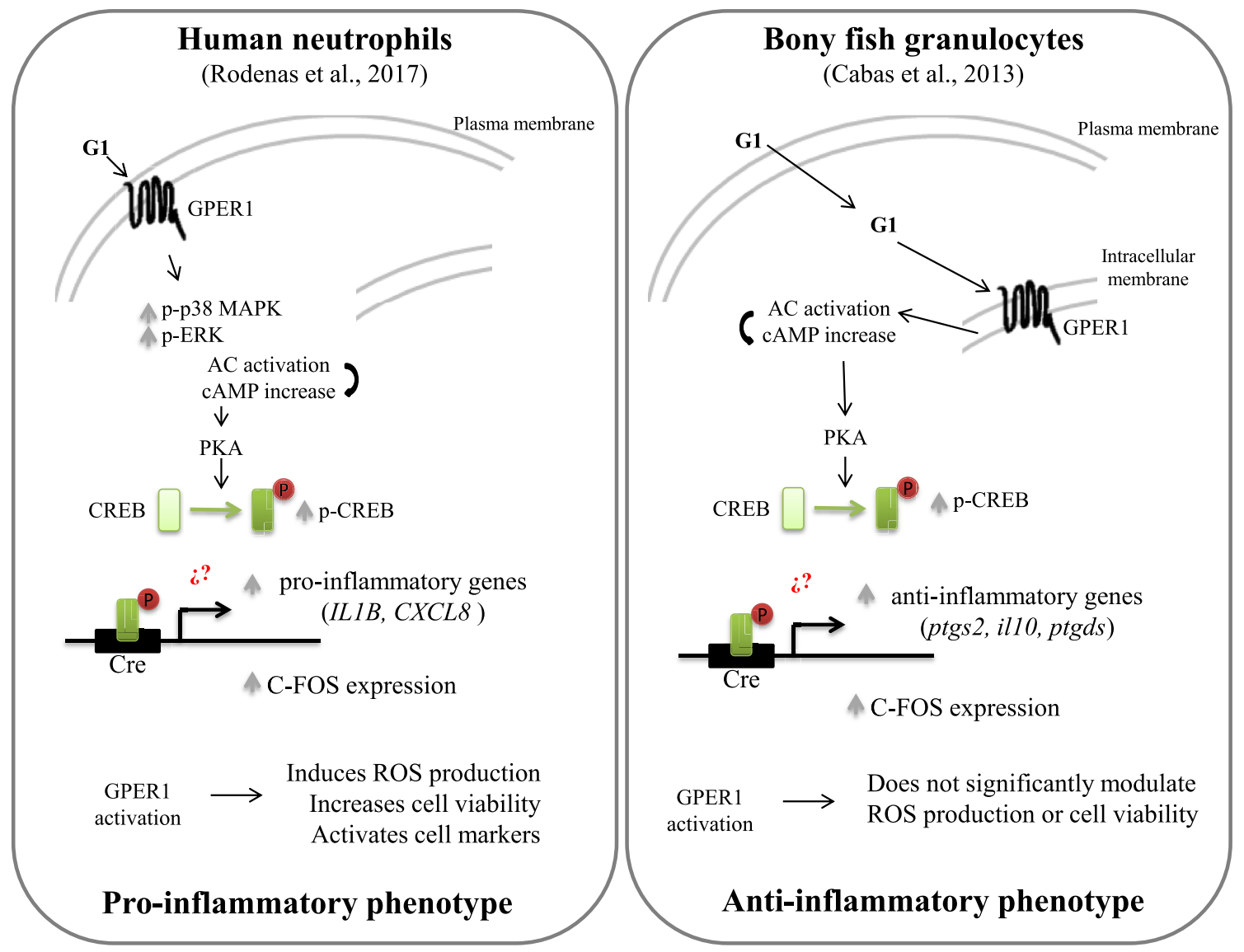

Fig. 1. Simplified scheme of the effects and signaling pathways described for GPER1 activation (by G1, a GPER1 specific agonist) in human neutrophils (left) and bony fish granulocytes (right). The results demonstrated in the cited papers are indicated with light-grey arrows. For more detail see at the end of section 3.2 .

necessary to activate GPER1 might not be the same in these different animal groups. On the other hand, as it has been reviewed by other authors, the subcellular localization of GPER1 is a controversial aspect (Langer et al., 2010). In the mentioned study which focuses on fish granulocytes (Cabas et al., 2013), it has been described an intracellular membrane localization of GPER1 since the GPER1 staining was only detected by using intracellular staining procedure, but not by extracellular staining one. Moreover, the evidence of GPER1 mediating estrogen response in these immune cells is that by using its specific agonist it was observed a significant induction in the $c$-fos expression levels and some immune-related changes. Furthermore, as it has been indicated in section 3.2 of this manuscript, a previous paper (Liarte et al., 2011b) described that these key cells did not express any of nuclear ERs identified in this fish species, so, the changes observed had to be only related with GPER1 activation. In the human neutrophils study, GPER1 staining was detected by using extracellular staining procedure (with live neutrophils), so, indicating a plasma membrane localization. Moreover, this result was further confirmed by subcellular fractionation studies, in which GPER1 was found to be present in the light membrane (secretory vesicles plus plasma membrane) fraction (Rodenas et al., 2017a). Therefore, other factors involved in the mentioned different effects would be the subcellular localization of GPER1, and the subsequent signaling pathways activated, the pool of ERs present in these cells, and the maturation and activation stage of them, among others, but it needs to be confirmed. Why GPER1 activation could lead different effects in immune cells and what is the physiological meaning of it, is unknown and need to be explored in more immune cells type and species.

\section{Concluding remarks}

Although there are controversial data, as occurs in mammals, estrogens clearly have the capacity to modulate fish immunity. In this way, it has been shown that in both fish and mammals estrogens can modulate all major innate and adaptive immune cells, affecting a wide range of immune aspects. So, the immunomodulatory role of estrogens is conserved along evolution, indicating the importance of the interaction between estrogens and immune response. Moreover, the fact that estrogens-mediated effects on immunity can vary depending on several factors (including concentration used, the time of exposure, immune cell type and their maturation stage, pool of ERs involved, among others) has been shown in both mammals and fish, showing that the immunomodulatory role of estrogen in very complex, as in mammals (Straub, 2007).

Even though this is a well-established fact, the physiological meaning of that interaction remains little understood and complex to determine in some contexts. Nevertheless, it is clear there is a fine-tune control of immune response by estrogens in several contexts such as inflammation, autoimmunity, infection, etc. In this way, it has been demonstrated by multiple facts such as: expression of ERs can be modulated by immune stimuli, estrogens are able to alter the expression of immune receptors, some immune genes contain ERE in their promoter regions, ERs are expressed in immune tissues during early development stages, and immune cells express steroidogenic enzymes, among others. Moreover, the differential expression of ERs in different tissues and cell types balances the estrogens mediated effects.

The physiological importance of the estrogens-mediated effects on immune response has been shown more clearly in mammals and in several contexts. It has been described that estrogens are able to control inflammation and are involved in its resolution (Villa et al., 2015), have 
a neuroprotective effect (Hernandez-Fonseca et al., 2012), and are in part responsible of the gender differences observed in some immune disorders (González et al., 2010). In support of this last statement, it is known that female have lower rates of infection and resultant mortality than male, but they have an overall increased rate of autoimmune diseases. In addition, the clinical symptoms of some of these immune disorders vary in relation to estrogen levels, in both female and male patients (Cemil et al., 2015; Lin and Huang, 2016). On the other hand, immune privilege is another context where importance of estrogensimmunity interaction is highlighted. It is known that some tissue such as placenta, fetus or reproductive organs have an immune privilege, being able to tolerate the introduction of antigens without eliciting an inflammatory immune response. In this context, it has been described in mammals that $\mathrm{T}$ regulatory cells play a critical role in downregulating immune responses, directing immune response toward tolerance (Zenclussen, 2006) and that estrogens promote the expansion and frequency of these key cells (Tai et al., 2008). Moreover, these cells are related with the protective effects of estrogen in autoimmune conditions (Offner and Polanczyk, 2006). In addition, as mentioned above, GPER1 activation modulates these cells in mammals (Brunsing et al., 2013), and, even in fish, it has been shown that estrogens regulate Foxp3, a transcription factor crucial in the activation of $\mathrm{T}$ regulatory cells (Wei et al., 2013). Another crucial context in mammals in which estrogens-immune interaction take part is during pregnancy, where high levels of estrogens observed in this period suppress many cytotoxic and innate immune responses, but stimulate antibody production, neoangiogenesis and growth (Straub, 2007). In fish, the relevance of estrogen-immunity interactions is also demonstrated by the fact that seasonal changes of immune system correlate with estrogens levels (Szwejser et al., 2017c). Moreover, infection or immune privilege are other fish contexts where estrogen-immunity interactions take importance (Valero et al., 2018).

The study of the interaction between estrogens and immune responses in fish will help to understand its evolutionary history and relevance. Nevertheless, in-depth studies to determine the specific mechanisms involved in these estrogen-mediated effects in both mammals and fish are needed, since most of them are mediated via complex molecular mechanisms. Moreover, we propose that GPER1 signaling should be taken into account since this signaling can be involved on the described estrogen-mediated effects or with new ones yet to be explored, both in fish and mammals. The study of the presence and role of GPER1 in fish immune cells may identify this receptor as an evolutionary actor in estrogenic action and will help to determine whether its signaling pathway is evolutionarily conserved.

Hence, there are a need to perform future studies, for now very scarce or nonexistent, focused on determining: (i) the presence of GPER1 in immune cells of other fish species in order to confirm the evolutionary importance of it; (ii) the relevance and mechanism of GPER1 activation in key immune processes such as inflammation, infection, haematopoiesis and adaptive immune response, among others; and (iii) the intrinsic importance of GPER1 in immune cells, by overexpressing or downregulating its expression in specific immune cell types. All this information would have implication not only for fishrelated issues, but also for others, such as biomedicine, since GPER1 could be a potential target in some immune disorders in which estrogens take part.

\section{Author contributions}

All authors have collaborated in the writing and revision of the manuscript and they approved the final version.

\section{Conflicts of interest}

The authors declare no conflict of interest.

\section{Acknowledgments}

This work was funded with support from Fundación Séneca, CARM (19883/GERM/15).

\section{References}

Albanito, L., Madeo, A., Lappano, R., Vivacqua, A., Rago, V., Carpino, A., Oprea, T.I., Prossnitz, E.R., Musti, A.M., Ando, S., Maggiolini, M., 2007. G protein-coupled receptor 30 (GPR30) mediates gene expression changes and growth response to 17betaestradiol and selective GPR30 ligand G-1 in ovarian cancer cells. Canc. Res. 67, 1859-1866.

Alexander, S.P., Mathie, A., Peters, J.A., 2011. In: Guide to Receptors and Channels (GRAC), fifth ed. pp. S1-S324 Br J Pharmacol 164 Suppl 1.

Altarejos, J.Y., Montminy, M., 2011. CREB and the CRTC co-activators: sensors for hormonal and metabolic signals. Nat. Rev. Mol. Cell Biol. 12, 141-151.

Blasko, E., Haskell, C.A., Leung, S., Gualtieri, G., Halks-Miller, M., Mahmoudi, M., Dennis, M.K., Prossnitz, E.R., Karpus, W.J., Horuk, R., 2009. Beneficial role of the GPR30 agonist G-1 in an animal model of multiple sclerosis. J. Neuroimmunol. 214, 67-77.

Bologa, C.G., Revankar, C.M., Young, S.M., Edwards, B.S., Arterburn, J.B., Kiselyov, A.S., Parker, M.A., Tkachenko, S.E., Savchuck, N.P., Sklar, L.A., Oprea, T.I., Prossnitz, E.R., 2006. Virtual and biomolecular screening converge on a selective agonist for GPR30. Nat. Chem. Biol. 2, 207-212.

Brunsing, R.L., Owens, K.S., Prossnitz, E.R., 2013. The G protein-coupled estrogen receptor (GPER) agonist G-1 expands the regulatory T-cell population under TH17polarizing conditions. J. Immunother. 36, 190-196.

Brunsing, R.L., Prossnitz, E.R., 2011. Induction of interleukin-10 in the Thelper type 17 effector population by the G protein coupled estrogen receptor (GPER) agonist G-1. Immunology 134, 93-106.

Burgos-Aceves, M.A., Cohen, A., Smith, Y., Faggio, C., 2016. Estrogen regulation of gene expression in the teleost fish immune system. Fish Shellfish Immunol. 58, 42-49.

Burgos-Aceves, M.A., Cohen, A., Smith, Y., Faggio, C., 2018. MicroRNAs and their role on fish oxidative stress during xenobiotic environmental exposures. Ecotoxicol. Environ. Saf. $148,995-1000$.

Cabas, I., Liarte, S., Garcia-Alcazar, A., Meseguer, J., Mulero, V., Garcia-Ayala, A., 2012. 17alpha-Ethynylestradiol alters the immune response of the teleost gilthead seabream (Sparus aurata L.) both in vivo and in vitro. Dev. Comp. Immunol. 36, 547-556.

Cabas, I., Rodenas, M.C., Abellan, E., Meseguer, J., Mulero, V., Garcia-Ayala, A., 2013. Estrogen signaling through the $\mathrm{G}$ protein-coupled estrogen receptor regulates granulocyte activation in fish. J. Immunol. 191, 4628-4639.

Casanova-Nakayama, A., Wenger, M., Burki, R., Eppler, E., Krasnov, A., Segner, H., 2011 Endocrine disrupting compounds: can they target the immune system of fish? Mar. Pollut. Bull. 63, 412-416.

Caviola, E., Dalla Valle, L., Belvedere, P., Colombo, L., 2007. Characterisation of three variants of estrogen receptor beta mRNA in the common sole, Solea solea L. (Teleostei). Gen. Comp. Endocrinol. 153, 31-39.

Cemil, B.C., Cengiz, F.P., Atas, H., Ozturk, G., Canpolat, F., 2015. Sex hormones in male psoriasis patients and their correlation with the Psoriasis Area and Severity Index. J. Dermatol. 42, 500-503.

Chakraborty, T., Shibata, Y., Zhou, L.Y., Katsu, Y., Iguchi, T., Nagahama, Y., 2011. Differential expression of three estrogen receptor subtype mRNAs in gonads and liver from embryos to adults of the medaka, Oryzias latipes. Mol. Cell. Endocrinol. 333, 47-54.

Chaves-Pozo, E., Pelegrin, P., Mulero, V., Meseguer, J., Garcia Ayala, A., 2003. A role for acidophilic granulocytes in the testis of the gilthead seabream (Sparus aurata L., Teleostei). J. Endocrinol. 179, 165-174.

Chawla, A., Repa, J.J., Evans, R.M., Mangelsdorf, D.J., 2001. Nuclear receptors and lipid physiology: opening the X-files. Science 294, 1866-1870.

Cote, M., Bourque, M., Poirier, A.A., Aube, B., Morissette, M., Di Paolo, T., Soulet, D., 2015. GPER1-mediated immunomodulation and neuroprotection in the myenteric plexus of a mouse model of Parkinson's disease. Neurobiol. Dis. 82, 99-113.

Cuesta, A., Vargas-Chacoff, L., Garcia-Lopez, A., Arjona, F.J., Martinez-Rodriguez, G., Meseguer, J., Mancera, J.M., Esteban, M.A., 2007. Effect of sex-steroid hormones, testosterone and estradiol, on humoral immune parameters of gilthead seabream. Fish Shellfish Immunol. 23, 693-700.

Danilova, N., Bussmann, J., Jekosch, K., Steiner, L.A., 2005. The immunoglobulin heavychain locus in zebrafish: identification and expression of a previously unknown isotype, immunoglobulin Z. Nat. Immunol. 6, 295-302.

Dennis, M.K., Burai, R., Ramesh, C., Petrie, W.K., Alcon, S.N., Nayak, T.K., Bologa, C.G., Leitao, A., Brailoiu, E., Deliu, E., Dun, N.J., Sklar, L.A., Hathaway, H.J., Arterburn, J.B., Oprea, T.I., Prossnitz, E.R., 2009. In vivo effects of a GPR30 antagonist. Nat. Chem. Biol. 5, 421-427.

Dennis, M.K., Field, A.S., Burai, R., Ramesh, C., Petrie, W.K., Bologa, C.G., Oprea, T.I., Yamaguchi, Y., Hayashi, S., Sklar, L.A., Hathaway, H.J., Arterburn, J.B., Prossnitz, E.R., 2011. Identification of a GPER/GPR30 antagonist with improved estrogen receptor counterselectivity. J. Steroid Biochem. Mol. Biol. 127, 358-366.

Dermaku-Sopjani, M., Abazi, S., Faggio, C., Kolgeci, J., Sopjani, M., 2014. AMPK-sensitive cellular transport. J. Biochem. 155, 147-158.

Deroo, B.J., Korach, K.S., 2006. Estrogen receptors and human disease. J. Clin. Invest. $116,561-570$.

Di Vito, C., Bergante, S., Balduini, A., Rastoldo, A., Bagarotti, A., Surico, N., Bertoni, A., Sinigaglia, F., 2010. The oestrogen receptor GPER is expressed in human haematopoietic stem cells but not in mature megakaryocytes. Br. J. Haematol. 149, 150-152.

Edholm, E.S., Bengten, E., Wilson, M., 2011. Insights into the function of IgD. Dev. Comp. 
Immunol. 35, 1309-1316.

Eick, G.N., Thornton, J.W., 2011. Evolution of steroid receptors from an estrogen-sensitive ancestral receptor. Mol. Cell. Endocrinol. 334, 31-38.

Evans, W.H., Bergeron, J.J., 1988. Nuclear receptors: a re-evaluation. Trends Biochem. Sci. 13, 7-8.

Filardo, E., Quinn, J., Pang, Y., Graeber, C., Shaw, S., Dong, J., Thomas, P., 2007. Activation of the novel estrogen receptor G protein-coupled receptor 30 (GPR30) at the plasma membrane. Endocrinology 148, 3236-3245.

Filardo, E.J., 2000. Estrogen-induced activation of Erk-1 and Erk-2 Requires the G Protein-coupled receptor homolog, GPR30, and occurs via trans-activation of the epidermal growth factor receptor through release of HB-EGF. Mol. Endocrinol. 14, 1649-1660.

Filardo, E.J., 2002. Estrogen action Via the G Protein-coupled receptor, GPR30: stimulation of adenylyl cyclase and cAMP-mediated attenuation of the epidermal growth factor receptor-to-MAPK signaling Axis. Mol. Endocrinol. 16, 70-84.

Funakoshi, T., Yanai, A., Shinoda, K., Kawano, M.M., Mizukami, Y., 2006. G proteincoupled receptor 30 is an estrogen receptor in the plasma membrane. Biochem. Biophys. Res. Commun. 346, 904-910.

Ghisletti, S., Meda, C., Maggi, A., Vegeto, E., 2005. 17beta-estradiol inhibits inflammatory gene expression by controlling NF-kappaB intracellular localization. Mol. Cell Biol. 25, 2957-2968.

Gilliver, S.C., 2010. Sex steroids as inflammatory regulators. J. Steroid Biochem. Mol. Biol. 120, 105-115.

Goldstein, S.R., 2001. The effect of SERMs on the endometrium. Ann. N. Y. Acad. Sci. 949, 237-242.

Gomez Gonzalez, N.E., Cabas, I., Rodenas, M.C., Arizcun, M., Mulero, V., Garcia Ayala, A., 2017. 17alpha-Ethynylestradiol alters the peritoneal immune response of gilthead seabream. Dev. Comp. Immunol. 76, 143-149.

González, D.A., Díaz, B.B., Rodríguez Pérez, M.d.C., Hernández, A.G., Chico, B.N.D., de León, A.C., 2010. Sex hormones and autoimmunity. Immunol. Lett. 133, 6-13.

Halm, S., Martinez-Rodriguez, G., Rodriguez, L., Prat, F., Mylonas, C.C., Carrillo, M., Zanuy, S., 2004. Cloning, characterisation, and expression of three oestrogen receptors (ERalpha, ERbeta1 and ERbeta2) in the European sea bass, Dicentrarchus labrax. Mol. Cell. Endocrinol. 223, 63-75.

Hawkins, M.B., Thornton, J.W., Crews, D., Skipper, J.K., Dotte, A., Thomas, P., 2000. Identification of a third distinct estrogen receptor and reclassification of estrogen receptors in teleosts. Proc. Natl. Acad. Sci. U. S. A. 97, 10751-10756.

Hernandez-Fonseca, K., Massieu, L., Garcia de la Cadena, S., Guzman, C., CamachoArroyo, I., 2012. Neuroprotective role of estradiol against neuronal death induced by glucose deprivation in cultured rat hippocampal neurons. Neuroendocrinology 96, 41-50.

Hess, R.A., 2003. Estrogen in the adult male reproductive tract: a review. Reprod. Biol Endocrinol. 1, 52

Hou, Y., Suzuki, Y., Aida, K., 1999. Effects of steroid hormones on immunoglobulin M (IgM) in rainbow trout, Oncorhynchus mykiss. Fish Physiol. Biochem. 20, 155-162.

Isensee, J., Meoli, L., Zazzu, V., Nabzdyk, C., Witt, H., Soewarto, D., Effertz, K., Fuchs, H., Gailus-Durner, V., Busch, D., Adler, T., de Angelis, M.H., Irgang, M., Otto, C., Noppinger, P.R., 2009. Expression pattern of G protein-coupled receptor 30 in LacZ reporter mice. Endocrinology 150, 1722-1730.

Iwanowicz, L.R., Stafford, J.L., Patino, R., Bengten, E., Miller, N.W., Blazer, V.S., 2014 Channel catfish (Ictalurus punctatus) leukocytes express estrogen receptor isoforms ERalpha and ERbeta2 and are functionally modulated by estrogens. Fish Shellfish Immunol. 40, 109-119.

Jacenik, D., Cygankiewicz, A.I., Fichna, J., Mokrowiecka, A., Malecka-Panas, E., Krajewska, W.M., 2017. Estrogen signaling deregulation related with local immune response modulation in irritable bowel syndrome. Mol. Cell. Endocrinol. 471, 89-96.

Katsu, Y., Lange, A., Miyagawa, S., Urushitani, H., Tatarazako, N., Kawashima, Y., Tyler, C.R., Iguchi, T., 2013. Cloning, expression and functional characterization of carp, Cyprinus carpio, estrogen receptors and their differential activations by estrogens. J. Appl. Toxicol. 33, 41-49.

Khan, D., Ansar Ahmed, S., 2015. The immune system is a natural target for estrogen action: opposing effects of estrogen in two prototypical autoimmune diseases. Front. Immunol. 6, 635.

Lafont, A.G., Rousseau, K., Tomkiewicz, J., Dufour, S., 2016. Three nuclear and two membrane estrogen receptors in basal teleosts, Anguilla sp.: identification, evolutionary history and differential expression regulation. Gen. Comp. Endocrinol. 235, 177-191.

Langer, G., Bader, B., Meoli, L., Isensee, J., Delbeck, M., Noppinger, P.R., Otto, C., 2010. A critical review of fundamental controversies in the field of GPR30 research. Steroids 75, 603-610.

Law, W.Y., Chen, W.H., Song, Y.L., Dufour, S., Chang, C.F., 2001. Differential in vitro suppressive effects of steroids on leukocyte phagocytosis in two teleosts, tilapia and common carp. Gen. Comp. Endocrinol. 121, 163-172.

Lewandowski, S.A., Thiery, J., Jalil, A., Leclercq, G., Szczylik, C., Chouaib, S., 2005. Opposite effects of estrogen receptors alpha and beta on MCF-7 sensitivity to the cytotoxic action of TNF and p53 activity. Oncogene 24, 4789-4798.

Liarte, S., Chaves-Pozo, E., Abellan, E., Meseguer, J., Mulero, V., Canario, A.V., GarciaAyala, A., 2011a. Estrogen-responsive genes in macrophages of the bony fish gilthead seabream: a transcriptomic approach. Dev. Comp. Immunol. 35, 840-849.

Liarte, S., Chaves-Pozo, E., Abellan, E., Meseguer, J., Mulero, V., Garcia-Ayala, A., 2011b. 17beta-Estradiol regulates gilthead seabream professional phagocyte responses through macrophage activation. Dev. Comp. Immunol. 35, 19-27.

Lin, X., Huang, T., 2016. Impact of pregnancy and oestrogen on psoriasis and potential therapeutic use of selective oestrogen receptor modulators for psoriasis. J. Eur. Acad. Dermatol. Venereol. 30, 1085-1091.

Liu, X., Zhu, P., Sham, K.W.Y., Yuen, J.M.L., Xie, C., Zhang, Y., Liu, Y., Li, S., Huang, X.,
Cheng, C.H.K., Lin, H., 2009. Identification of a membrane estrogen receptor in zebrafish with homology to mammalian GPER and its high expression in early germ cells of the Testis1. Biol. Reprod. 80, 1253-1261.

Lopez-Munoz, A., Liarte, S., Gomez-Gonzalez, N.E., Cabas, I., Meseguer, J., Garcia-Ayala, A., Mulero, V., 2015. Estrogen receptor 2b deficiency impairs the antiviral response of zebrafish. Dev. Comp. Immunol. 53, 55-62.

Ma, C.H., Dong, K.W., Yu, K.L., 2000. cDNA cloning and expression of a novel estrogen receptor beta-subtype in goldfish (Carassius auratus). Biochim. Biophys. Acta 1490, 145-152.

Ma, L., Pei, G., 2007. Beta-arrestin signaling and regulation of transcription. J. Cell Sci. 120, 213-218.

Magnadottir, B., 2006. Innate immunity of fish (overview). Fish Shellfish Immunol. 20, 137-151.

Majumder, S., Das, S., Moulik, S.R., Mallick, B., Pal, P., Mukherjee, D., 2015. G-protein coupled estrogen receptor (GPER) inhibits final oocyte maturation in common carp, Cyprinus carpio. Gen. Comp. Endocrinol. 211, 28-38.

Mangiamele, L.A., Gomez, J.R., Curtis, N.J., Thompson, R.R., 2017. GPER/GPR30, a membrane estrogen receptor, is expressed in the brain and retina of a social fish (Carassius auratus) and colocalizes with isotocin. J. Comp. Neurol. 525, 252-270.

Matthews, J., Gustafsson, J.A., 2003. Estrogen signaling: a subtle balance between ER alpha and ER beta. Mol. Interv. 3, 281-292.

Menuet, A., Pellegrini, E., Anglade, I., Blaise, O., Laudet, V., Kah, O., Pakdel, F., 2002. Molecular characterization of three estrogen receptor forms in zebrafish: binding characteristics, transactivation properties, and tissue distributions. Biol. Reprod. 66, 1881-1892.

Mizukami, Y., 2010. In vivo functions of GPR30/GPER-1, a membrane receptor for estrogen: from discovery to functions in vivo. Endocr. J. 57, 101-107.

Moriarty, K., Kim, K.H., Bender, J.R., 2006. Minireview: estrogen receptor-mediated rapid signaling. Endocrinology 147, 5557-5563.

Morini, M., Penaranda, D.S., Vilchez, M.C., Tveiten, H., Lafont, A.G., Dufour, S., Perez, L., Asturiano, J.F., 2017. The expression of nuclear and membrane estrogen receptors in the European eel throughout spermatogenesis. Comp. Biochem. Physiol. Mol. Integr. Physiol. 203, 91-99.

Mutoloki, S., Jørgensen, J.B., Evensen, Ø., 2014. The adaptive immune response in fish. Fish Vaccination 9, 104-115.

Nagarajan, G., Tsai, Y.J., Chen, C.Y., Chang, C.F., 2011. Developmental expression of genes involved in neural estrogen biosynthesis and signaling in the brain of the orange-spotted grouper Epinephelus coioides during gonadal sex differentiation. J. Steroid Biochem. Mol. Biol. 127, 155-166.

Nagler, J.J., Cavileer, T., Sullivan, J., Cyr, D.G., Rexroad 3rd, C., 2007. The complete nuclear estrogen receptor family in the rainbow trout: discovery of the novel ERalpha2 and both ERbeta isoforms. Gene 392, 164-173.

Nakamura, Y., Miki, Y., Suzuki, T., Nakata, T., Darnel, A.D., Moriya, T., Tazawa, C., Saito, H., Ishibashi, T., Takahashi, S., Yamada, S., Sasano, H., 2003. Steroid sulfatase and estrogen sulfotransferase in the atherosclerotic human aorta. Am. J. Pathol. 163, 1329-1339.

Nelson, L.R., Bulun, S.E., 2001. Estrogen production and action. J. Am. Acad. Dermatol. 45, S116-S124.

Nikoleris, L., Hansson, M.C., 2015. Unraveling the estrogen receptor (er) genes in Atlantic salmon (Salmo salar) reveals expression differences between the two adult life stages but little impact from polychlorinated biphenyl (PCB) load. Mol. Cell. Endocrinol. 400, 10-20.

Offner, H., Polanczyk, M., 2006. A potential role for estrogen in experimental autoimmune encephalomyelitis and multiple sclerosis. Ann. N. Y. Acad. Sci. 1089 343-372.

Olde, B., Leeb-Lundberg, L.M., 2009. GPR30/GPER1: searching for a role in estrogen physiology. Trends Endocrinol. Metabol. 20, 409-416.

Paiola, M., Knigge, T., Picchietti, S., Duflot, A., Guerra, L., Pinto, P.I.S., Scapigliati, G. Monsinjon, T., 2017. Oestrogen receptor distribution related to functional thymus anatomy of the European sea bass, Dicentrarchus labrax. Dev. Comp. Immunol. 77, 106-120.

Pang, Y., Dong, J., Thomas, P., 2008. Estrogen signaling characteristics of Atlantic croaker G protein-coupled receptor 30 (GPR30) and evidence it is involved in maintenance of oocyte meiotic arrest. Endocrinology 149, 3410-3426.

Pang, Y., Thomas, P., 2009. Involvement of estradiol-17beta and its membrane receptor, G protein coupled receptor 30 (GPR30) in regulation of oocyte maturation in zebrafish, Danio rario. Gen. Comp. Endocrinol. 161, 58-61.

Pedram, A., Razandi, M., Levin, E.R., 2006. Nature of functional estrogen receptors at the plasma membrane. Mol. Endocrinol. 20, 1996-2009.

Pinto, P., Passos, A.L., Power, D.M., CanÁRio, A.V.M., 2005. Sea bream (sparus auratus) estrogen receptors: phylogeny and tissue distribution. Ann. N. Y. Acad. Sci. 1040, 436-438.

Pinto, P.I.S., Andrade, A.R., Estevao, M.D., Alvarado, M.V., Felip, A., Power, D.M., 2017. Duplicated membrane estrogen receptors in the European sea bass (Dicentrarchus labrax): phylogeny, expression and regulation throughout the reproductive cycle. J. Steroid Biochem. Mol. Biol. 178, 234-242.

Pinto, P.I.S., Passos, A.L., Martins, D.M.P.R.S., Canário, A.V.M., 2006. Characterization of estrogen receptor $\beta \mathrm{b}$ in sea bream (Sparus auratus): phylogeny, ligand-binding, and comparative analysis of expression. Gen. Comp. Endocrinol. 145, 197-207.

Prossnitz, E.R., Barton, M., 2009. Signaling, physiological functions and clinical relevance of the G protein-coupled estrogen receptor GPER. Prostag. Other Lipid Mediat. 89, 89-97.

Prossnitz, E.R., Barton, M., 2011. The G-protein-coupled estrogen receptor GPER in health and disease. Nat. Rev. Endocrinol. 7, 715-726.

Prossnitz, E.R., Hathaway, H.J., 2015. What have we learned about GPER function in physiology and disease from knockout mice? J. Steroid Biochem. Mol. Biol. 153, 
$114-126$.

Prossnitz, E.R., Maggiolini, M., 2009. Mechanisms of estrogen signaling and gene expression via GPR30. Mol. Cell. Endocrinol. 308, 32-38.

Rettew, J.A., McCall, S.H.t., Marriott, I., 2010. GPR30/GPER-1 mediates rapid decreases in TLR4 expression on murine macrophages. Mol. Cell. Endocrinol. 328, 87-92.

Revankar, C.M., 2005. A transmembrane intracellular estrogen receptor mediates rapid cell signaling. Science 307, 1625-1630.

Rodenas, M., Tamassia, N., Cabas, I., Calzetti, F., Meseguer, J., Cassatella, M., GarcíaAyala, A., Mulero, V., 2017a. G protein-coupled estrogen receptor 1 regulates human neutrophil functions. Biomed Hub 2, 454981.

Rodenas, M.C., Cabas, I., Abellan, E., Meseguer, J., Mulero, V., Garcia-Ayala, A., 2015. Tamoxifen persistently disrupts the humoral adaptive immune response of gilthead seabream (Sparus aurata L.). Dev. Comp. Immunol. 53, 283-292.

Rodenas, M.C., Cabas, I., Gomez-Gonzalez, N.E., Arizcun, M., Meseguer, J., Mulero, V., Garcia-Ayala, A., 2017b. Estrogens promote the production of natural neutralizing antibodies in Fish through G Protein-coupled estrogen receptor 1. Front. Immunol. 8, 736.

Romano, S.N., Edwards, H.E., Souder, J.P., Ryan, K.J., Cui, X., Gorelick, D.A., 2017. G protein-coupled estrogen receptor regulates embryonic heart rate in zebrafish. PLoS Genet. 13, e1007069.

Saha, N.R., Usami, T., Suzuki, Y., 2004. In vitro effects of steroid hormones on IgMsecreting cells and IgM secretion in common carp (Cyprinus carpio). Fish Shellfish Immunol. 17, 149-158.

Salinas, I., 2015. The mucosal immune system of teleost fish. Biology 4, 525-539.

Schneider, A.E., Karpati, E., Schuszter, K., Toth, E.A., Kiss, E., Kulcsar, M., Laszlo, G., Matko, J., 2014. A dynamic network of estrogen receptors in murine lymphocytes: fine-tuning the immune response. J. Leukoc. Biol. 96, 857-872.

Seemann, F., Knigge, T., Duflot, A., Marie, S., Olivier, S., Minier, C., Monsinjon, T., 2016. Sensitive periods for 17beta-estradiol exposure during immune system development in sea bass head kidney. J. Appl. Toxicol. 36, 815-826.

Seemann, F., Knigge, T., Olivier, S., Monsinjon, T., 2015. Exogenous 17beta-oestradiol (E2) modifies thymus growth and regionalization in European sea bass Dicentrarchus labrax. J. Fish. Biol. 86, 1186-1198.

Seemann, F., Knigge, T., Rocher, B., Minier, C., Monsinjon, T., 2013. 17beta-Estradiol induces changes in cytokine levels in head kidney and blood of juvenile sea bass (Dicentrarchus labrax, L., 1758). Mar. Environ. Res. 87-88, 44-51.

Sepulcre, M.P., Pelegrin, P., Mulero, V., Meseguer, J., 2002. Characterisation of gilthead seabream acidophilic granulocytes by a monoclonal antibody unequivocally points to their involvement in fish phagocytic response. Cell Tissue Res. 308, 97-102.

Shelley, L.K., Osachoff, H.L., van Aggelen, G.C., Ross, P.S., Kennedy, C.J., 2013. Alteration of immune function endpoints and differential expression of estrogen receptor isoforms in leukocytes from 17beta-estradiol exposed rainbow trout (Oncorhynchus mykiss). Gen. Comp. Endocrinol. 180, 24-32.

Shi, Y., Liu, X., Zhu, P., Li, J., Sham, K.W.Y., Cheng, S.H., Li, S., Zhang, Y., Cheng, C.H.K., Lin, H., 2013. G-protein-coupled estrogen receptor 1 is involved in brain development during zebrafish (Danio rerio) embryogenesis. Biochem. Biophys. Res. Commun. 435, 21-27.

Simpkins, J.W., Yang, S.H., Sarkar, S.N., Pearce, V., 2008. Estrogen actions on mitochondria-physiological and pathological implications. Mol. Cell. Endocrinol. 290, 51-59.

Straub, R.H., 2007. The complex role of estrogens in inflammation. Endocr. Rev. 28, 521-574.

Sun, Q., Liang, Y., Zhang, T., Wang, K., Yang, X., 2017. ER-alpha36 mediates estrogenstimulated MAPK/ERK activation and regulates migration, invasion, proliferation in cervical cancer cells. Biochem. Biophys. Res. Commun. 487, 625-632.

Szwejser, E., Maciuszek, M., Casanova-Nakayama, A., Segner, H., Verburg-van Kemenade, B.M.L., Chadzinska, M., 2017a. A role for multiple estrogen receptors in immune regulation of common carp. Dev. Comp. Immunol. 66, 61-72.

Szwejser, E., Pijanowski, L., Maciuszek, M., Ptak, A., Wartalski, K., Duda, M., Segner, H., Verburg-van Kemenade, B.M.L., Chadzinska, M., 2017b. Stress differentially affects the systemic and leukocyte estrogen network in common carp. Fish Shellfish Immunol. 68, 190-201.

Szwejser, E., Verburg-van Kemenade, B.M., Maciuszek, M., Chadzinska, M., 2017c. Estrogen-dependent seasonal adaptations in the immune response of fish. Horm. Behav. 88, 15-24.

Tai, P., Wang, J., Jin, H., Song, X., Yan, J., Kang, Y., Zhao, L., An, X., Du, X., Chen, X. Wang, S., Xia, G., Wang, B., 2008. Induction of regulatory T cells by physiological level estrogen. J. Cell. Physiol. 214, 456-464.

Tamaki, M., Konno, Y., Kobayashi, Y., Takeda, M., Itoga, M., Moritoki, Y., Oyamada, H., Kayaba, H., Chihara, J., Ueki, S., 2014. Expression and functional roles of G-proteincoupled estrogen receptor (GPER) in human eosinophils. Immunol. Lett. 160, 72-78.
Thilagam, H., Gopalakrishnan, S., Bo, J., Wang, K.J., 2009. Effect of 17beta-estradiol on the immunocompetence of Japanese sea bass (Lateolabrax japonicus). Environ. Toxicol. Chem. 28, 1722-1731.

Thomas, P., Alyea, R., Pang, Y., Peyton, C., Dong, J., Berg, A.H., 2010. Conserved estrogen binding and signaling functions of the $\mathrm{G}$ protein-coupled estrogen receptor 1 (GPER) in mammals and fish. Steroids 75, 595-602.

Thomas, P., Pang, Y., Filardo, E.J., Dong, J., 2005. Identity of an estrogen membrane receptor coupled to a $\mathrm{G}$ protein in human breast cancer cells. Endocrinology 146, 624-632.

Tohyama, S., Miyagawa, S., Lange, A., Ogino, Y., Mizutani, T., Ihara, M., Tanaka, H., Tatarazako, N., Kobayashi, T., Tyler, C.R., Iguchi, T., 2016. Evolution of estrogen receptors in ray-finned fish and their comparative responses to estrogenic substances. J. Steroid Biochem. Mol. Biol. 158, 189-197.

Valero, Y., Cuesta, A., Cammarata, M., Esteban, M.A., Chaves-Pozo, E., 2018. Immuneendocrine interactions in the fish gonad during infection: an open door to vertical transmission. Fishes 3, 1-22.

Villa, A., Rizzi, N., Vegeto, E., Ciana, P., Maggi, A., 2015. Estrogen accelerates the resolution of inflammation in macrophagic cells. Sci. Rep. 5.

Wahli, W., Martinez, E., 1991. Superfamily of steroid nuclear receptors: positive and negative regulators of gene expression. Faseb. J. 5, 2243-2249.

Wang, C., Dehghani, B., Li, Y., Kaler, L.J., Proctor, T., Vandenbark, A.A., Offner, H., 2009. Membrane estrogen receptor regulates experimental autoimmune encephalomyelitis through up-regulation of programmed death 1. J. Immunol. 182, 3294-3303.

Wang, C., Dehghani, B., Magrisso, I.J., Rick, E.A., Bonhomme, E., Cody, D.B., Elenich, L.A., Subramanian, S., Murphy, S.J., Kelly, M.J., Rosenbaum, J.S., Vandenbark, A.A., Offner, H., 2008. GPR30 contributes to estrogen-induced thymic atrophy. Mol. Endocrinol. 22, 636-648.

Wang, D., Hu, L., Zhang, G., Zhang, L., Chen, C., 2010. G protein-coupled receptor 30 in tumor development. Endocrine 38, 29-37.

Wang, R., Belosevic, M., 1994. Estradiol increases susceptibility of goldfish to Trypanosoma danilewskyi. Dev. Comp. Immunol. 18, 377-387.

Watanuki, H., Yamaguchi, T., Sakai, M., 2002. Suppression in function of phagocytic cells in common carp Cyprinus carpio L. injected with estradiol, progesterone or 11-ketotestosterone. Comp. Biochem. Physiol. C Toxicol. Pharmacol. 132, 407-413.

Watson, C.S., Jeng, Y.J., Guptarak, J., 2011. Endocrine disruption via estrogen receptors that participate in nongenomic signaling pathways. J. Steroid Biochem. Mol. Biol. 127, 44-50.

Wei, J., Yu, L., Sun, L., Zhang, X., Li, M., Qi, W., Zhou, L., Wang, D., 2013. Molecular cloning and expression analysis of Foxp3 from Nile tilapia. Vet. Immunol. Immunopathol. 155, 48-56.

Wenger, M., Sattler, U., Goldschmidt-Clermont, E., Segner, H., 2011. 17Beta-estradiol affects the response of complement components and survival of rainbow trout (Oncorhynchus mykiss) challenged by bacterial infection. Fish Shellfish Immunol. 31, 90-97.

Wenger, M., Shved, N., Akgul, G., Caelers, A., Casanova, A., Segner, H., Eppler, E., 2014 Developmental oestrogen exposure differentially modulates IGF-I and TNF-alpha expression levels in immune organs of Yersinia ruckeri-challenged young adult rainbow trout (Oncorhynchus mykiss). Gen. Comp. Endocrinol. 205, 168-175.

Xia, Z., Gale, W.L., Chang, X., Langenau, D., Patino, R., Maule, A.G., Densmore, L.D., 2000. Phylogenetic sequence analysis, recombinant expression, and tissue distribution of a channel catfish estrogen receptor beta. Gen. Comp. Endocrinol. 118, 139-149.

Yamaguchi, T., Watanuki, H., Sakai, M., 2001. Effects of estradiol, progesterone and testosterone on the function of carp, Cyprinus carpio, phagocytes in vitro. Comp. Biochem. Physiol. C Toxicol. Pharmacol. 129, 49-55.

Yan, Y., Yu, L., Castro, L., Dixon, D., 2017. ERalpha36, a variant of estrogen receptor alpha, is predominantly localized in mitochondria of human uterine smooth muscle and leiomyoma cells. PLoS One 12, e0186078.

Zenclussen, A.C., 2006. Regulatory T Cells in Pregnancy 28. Springer Semin Immunopathol, pp. 31-39.

Zhang, Y.A., Salinas, I., Li, J., Parra, D., Bjork, S., Xu, Z., LaPatra, S.E., Bartholomew, J., Sunyer, J.O., 2010. IgT, a primitive immunoglobulin class specialized in mucosal immunity. Nat. Immunol. 11, 827-835.

Zheng, Y., Wang, L., Li, M., Liang, H., Qin, F., Liu, S., Wang, H., Wu, T., Zhang, Y., Wang, Z., 2013. Molecular characterization of five steroid receptors from pengze crucian carp and their expression profiles of juveniles in response to 17alpha-ethinylestradiol and 17alpha-methyltestosterone. Gen. Comp. Endocrinol. 191, 113-122.

Zhu, P., Zhang, Y., Zhuo, Q., Lu, D., Huang, J., Liu, X., Lin, H., 2008. Discovery of four estrogen receptors and their expression profiles during testis recrudescence in male Spinibarbus denticulatus. Gen. Comp. Endocrinol. 156, 265-276. 